\title{
El IVCR+i premio Europa Nostra 2018 por su proyecto de conservación de los bocetos de Sorolla Visión de España
}

Gemma María Contreras Zamorano, Elena Gandía Guijarro | Subdirección General del Institut Valencià de Conservació, Restauració i Investigació (IVCR+i) Generalitat Valenciana

URL de la contribución <www.iaph.es/revistaph/index.php/revistaph/article/view/4308>

\section{RESUMEN}

La Comisión Europea y Europa Nostra, la red más importante en materia de patrimonio europeo, ha otorgado el Premio Unión Europea de Patrimonio Cultural/Premios Europa Nostra 2018 al Institut Valencià de Conservació, Restauració i Investigació (IVCR+i), por su proyecto de conservaciónrestauración de Los bocetos de Sorolla de Visión de España, pertenecientes a la Hispanic Society of America (New York).

Este proyecto tuvo su culminación en la gran exposición temporal Sorolla íntimo, bocetos de "Visión de España", que permitió mostrar el proceso creativo de Sorolla a través de sus dibujos preparatorios y el complejo proceso de intervención de restauración realizado por los profesionales del IVCR+i, que utilizaron la técnica japonesa "soko" y los criterios más respetuosos y avanzados en conservación y restauración.

\section{Palabras clave}

Bocetos | Conservación | Grandes formatos | Institut Valencià de Conservació, Restauració i Investigació | Laminación | Premio Unión Europea de Patrimonio Cultural | Premio Europa Nostra | Restauración | Soko | Sorolla | 2018 | 


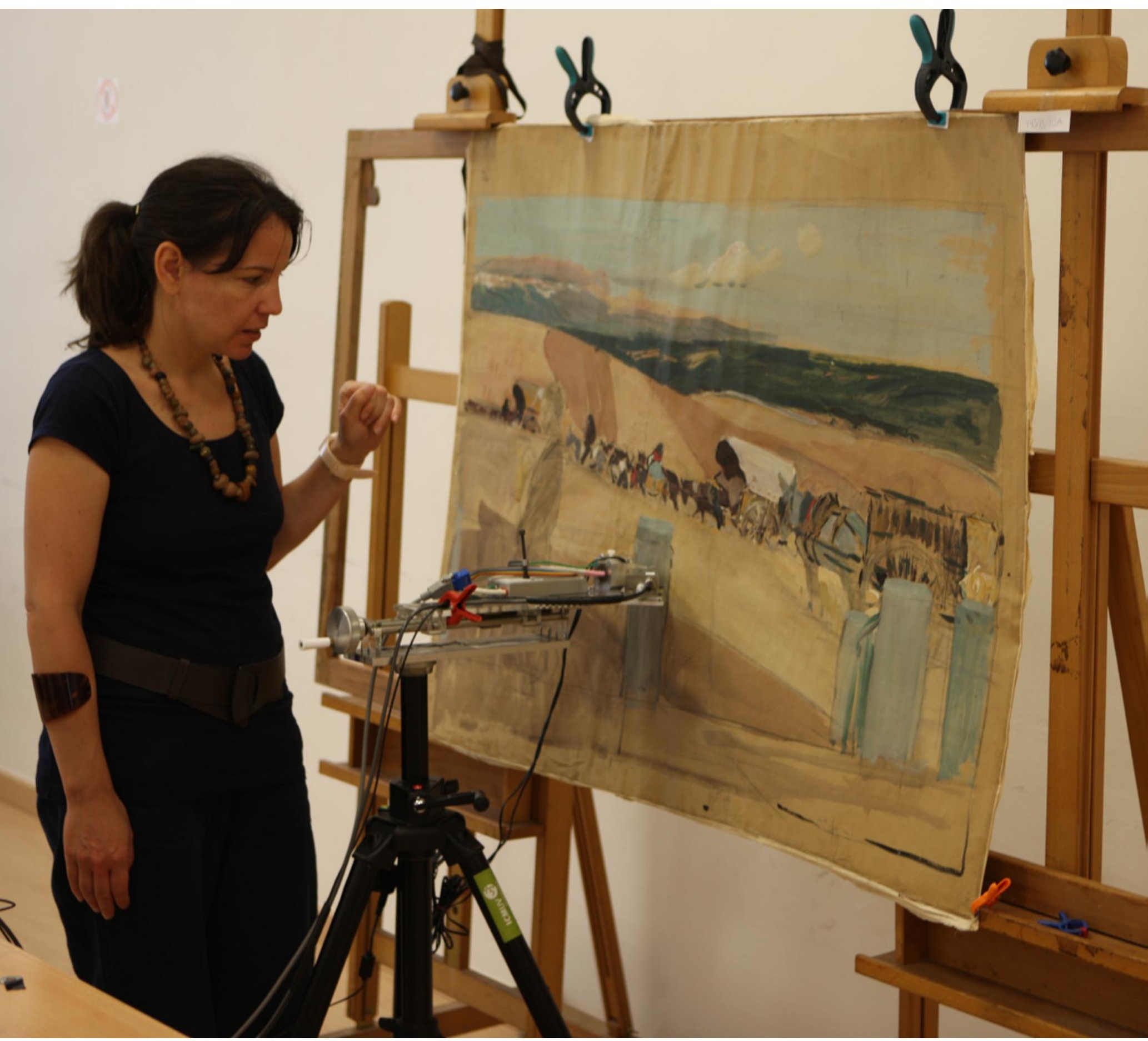

Estudio de los pigmentos con fluorescencia de Rayos X | foto Institut Valencià de Conservació, Restauració i Investigació (IVCR+i), titular de todas las imágenes que ilustran este artículo 
La Comisión Europea y Europa Nostra, la red más importante en materia de patrimonio europeo, han otorgado al Institut Valencià de Conservació, Restauració i Investigació (IVCR+i) el Premio Unión Europea de Patrimonio Cultural/Premio Europa Nostra en su edición de 2018, por el proyecto de restauración de los bocetos que Joaquín Sorolla realizó para su monumental serie pictórica Visión de España, premiando la contribución de este proyecto en el ámbito de la conservación del patrimonio cultural.

El IVCR+i es un organismo dependiente de la Generalitat Valenciana cuya misión principal es la salvaguarda del patrimonio cultural valenciano a través de proyectos de conservación, restauración e investigación, y su posterior difusión y comunicación. Para ello cuenta con un equipo multidisciplinar y con la colaboración de instituciones académicas y culturales a nivel nacional e internacional. El premio recibido supone un gran reconocimiento para el IVCR+i y, en especial, para el Departamento de Obra Gráfica y Material de Archivo, que ha demostrado ser puntero en su especialidad desde que se creara en 2006.

La otra gran institución que ha permitido la consecución de este proyecto de conservación es la Hispanic Society of America, con sede en Nueva York, creada para la divulgación y estudio de la cultura española en los Estados Unidos de América. Uno de los fondos artísticos más importantes que posee es la obra que Joaquín Sorolla realizó para decorar la Biblioteca de la Hispanic titulada Visión de España, cuyos dibujos preliminares han sido objeto de esta restauración y exposición.

La decisión de los conservadores de la Hispanic Society ha tenido como motivación recuperar obras de difícil intervención y al mismo tiempo hacerlas visibles a un público más amplio, ya que hasta ahora habían sido pocas las personas que habían podido apreciar su impacto no sólo en relación con los lienzos murales, sino como obras de arte extremadamente expresivas por sí mismas. Para ello se firmó un convenio con la Generalitat Valenciana, a través del IVCR+i, por el que la Hispanic Society financiaba el traslado de las obras a Valencia (España) y el IVCR+i se hacía cargo de la restauración de las obras y de organizar su posterior exhibición en una muestra itinerante, con la colaboración de la Fundación Bancaja.

Joaquín Sorolla nació en 1863 en Valencia, una ciudad española, mediterránea. En ella aprendió su oficio y se desarrolló como artista pero, sobre todo, se empapó de su luz y de sus paisajes. Su éxito lo lanzó a nivel internacional todavía en vida. Primero dio el salto a Madrid, después a París y Londres y, tras conocer a Archer Milton Huntington, traspasó el Atlántico y cautivó con su pintura al pueblo americano. La culminación de su obra fue el encargo que le realizó Huntington en 1911 de la serie de paneles al óleo conocida como Visión de España destinada a ilustrar, en las paredes de la 


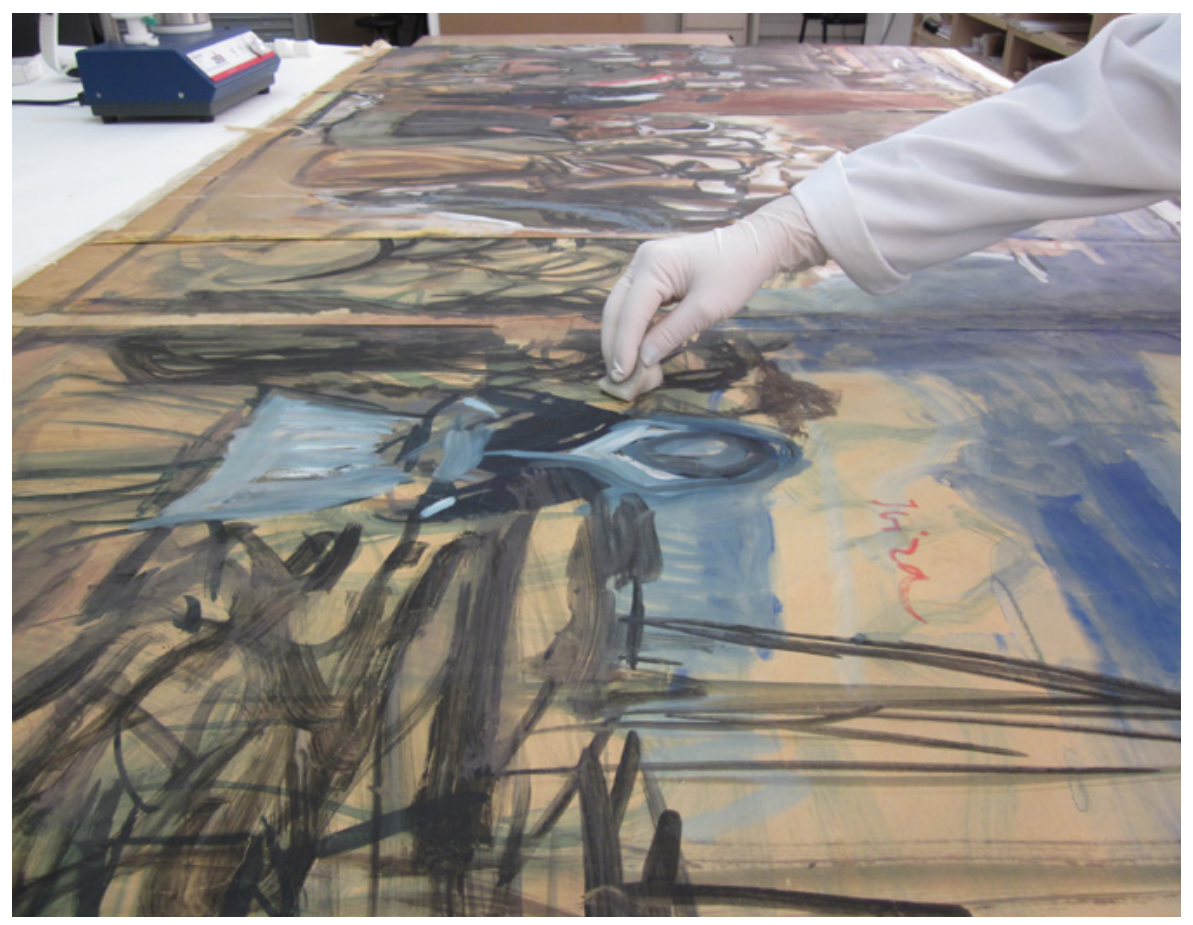

Biblioteca de la Hispanic Society, las diferentes regiones y tradiciones de España. En ella, Sorolla recogió el testigo de una España a punto de desaparecer y retrató personajes y costumbres de cada una de sus regiones. Huntington, conocedor del arte y capacidad de Sorolla, estipuló en el contrato que no sólo le correspondía la obra final, sino también sería suyo todo el proceso creativo, de gestación, previo. Sorolla viajó durante nueve años por España con rollos de papel que colgaba con chinchetas, en los que esbozaba del natural los aspectos que más le interesaban de esa España plural. Llegó a realizar un importante número de dibujos y lienzos preparatorios que, a modo de bocetos o apuntes directos, fue tomando por las distintas regiones de España.

El proyecto de restauración de los bocetos de Sorolla, abordado por el IVCR+i, puede considerarse la culminación de otro de mayor envergadura que comenzó en 2007 cuando la Fundación Bancaja promovió y financió la restauración de los 14 grandes lienzos de Visión de España que decoran la Biblioteca de la Hispanic Society of America. En aquella ocasión los lienzos se restauraron y viajaron por primera vez a España para ser mostrados en una gran exposición que se celebró en 2007 en el Centro Cultural Bancaja y, entre 2008 y 2009, en el Museo de Bellas Artes de Sevilla, en el Museo Municipal de Málaga, en el Museo Nacional de Arte de Cataluña y en el Museo de Bellas Artes de Bilbao, para finalizar su peregrinaje con la gran muestra celebrada en el Museo del Prado. 
1

BURKE, M. B.; PONS-SOROLLA, B.; PÉREZ, C. (2015) Sorolla Íntimo. Bocetos de Visión de España. [Valencia]: Fundación Bancaja, D. L. 2015, $189 \mathrm{p}$
Como colofón a este gran proyecto se decidió restaurar la obra gráfica que acompaña a este conjunto pictórico y devolverle así su inicial esplendor. Para ello, la Hispanic Society confió en los profesionales del IVCR+i, tanto del Departamento de Obra Gráfica y Material de Archivo, como de los departamentos de Pintura de Caballete y del Laboratorio de Materiales, que contó con la especial colaboración del Instituto de Estudio de Materiales de la Universitat de València.

Fue en el mes de abril de 2013 cuando llegaron al IVCR+i, desde Nueva York, treinta y dos bocetos totalmente inéditos de Sorolla, para ser intervenidos durante un periodo de 18 meses en su sede de Valencia. La segunda parte del proyecto, la puesta en valor tanto de las obras como del proceso de restauración, se plasmó en la exposición Sorolla Íntimo. Bocetos de Visión de España, organizada por la Fundación Bancaja en su Centro Cultural de Valencia en 2015. Dado el gran éxito de la muestra, se continuó con esa labor de difusión de la obra de Sorolla y, aprovechando los meses de verano que son los más turísticos en la Comunidad Valenciana, se exhibió en los Museos de Bellas Artes de Alicante y Castellón, para terminar su periplo español en el fantástico Museo de Bellas Artes de A Coruña a principios de 2017.

Gracias a la intervención se ha asegurado la pervivencia de estos grandes dibujos, algunos de los cuales miden más de un metro de altura por ocho de longitud, y cuya fragilidad los hace especialmente vulnerables. Se les ha dotado de soportes y marcos que garantizan su conservación preventiva a largo plazo. Los frágiles papeles con los que Sorolla aprehendió la España de inicios del siglo XX tienen asegurado un largo futuro que podrán apreciar y estudiar futuras generaciones. Por su parte, la exposición Sorolla Íntimo. Bocetos de Visión de España y el catálogo que la acompañaba ${ }^{1}$, han permitido dar a conocer estos singulares estudios que nunca se habían visto fuera de la Hispanic Society of America y, paralelamente, mostrar el proceso de investigación y restauración realizado por los técnicos del IVCR+i que han utilizado la técnica japonesa soko, y han adoptado los criterios más respetuosos y avanzados en conservación y restauración.

\section{ESTADO DE CONSERVACIÓN DE LAS OBRAS Y VALORACIÓN DEL PROYECTO DE CONSERVACIÓN-RESTAURACIÓN}

A finales de los años sesenta del siglo XX los conservadores de la Hispanic Society of America ya eran conscientes de que este importante conjunto de obra gráfica formado por más de ciento setenta bocetos, realizados con carboncillo o gouache sobre papel, necesitaba tratamiento de conservación. Numerosos acercamientos por parte de la Hispanic Society al Fondo Nacional para las Artes de los Estados Unidos a partir de 1968 fructificaron 
finalmente durante los años ochenta en la concesión de ayudas destinadas a una primera campaña de restauración. A ella le siguieron otras durante los noventa (asociadas con la exposición de 1998-99 Sorolla y la Hispanic Society en el Museo Thyssen-Bornemisza de Madrid), y también durante esta última década, ya en el siglo XXI.

Ahora, gracias a la dilatada colaboración entre la Hispanic Society y las instituciones culturales valencianas, el grupo final y más grande de bocetos, compuesto por 25 obras realizadas bajo la técnica del gouache sobre papel (32 hojas en total), ha podido ser restaurado, con lo que concluyen más de cuarenta años de esfuerzos por la conservación del conjunto.

Estos bocetos descubren el modo de trabajar de Joaquín Sorolla a la hora de componer los grandes lienzos de Visión de España, pues responden a apuntes del natural de personajes, objetos y paisajes, que posteriormente fue recomponiendo en su estudio mediante una técnica similar al collage, basada en recortar aquellas figuras o elementos que le gustaban y, con ellos, componer otro boceto hasta llegar a la composición definitiva. En otros casos son sólo los propios bocetos y apuntes, o en un tercer caso se trata de figuras recortadas y pegadas sobre otro papel para tener un catálogo de figuras o personajes que posteriormente pudiese utilizar en la composición pictórica. Por ello podemos decir que son tres modalidades de bocetos los que se han intervenido en esta ocasión.

En el IVCR+i se apuesta por un trabajo multidisciplinar que garantice un profundo conocimiento de las obras y permita una aproximación a las mismas desde distintos puntos de vista obteniendo un resultado más completo en función de las aportaciones y métodos empleados y determinando así tanto el estado de conservación como el protocolo y método de actuación que garanticen la preservación de las piezas.

Los bocetos que realizó Joaquín Sorolla son, en su mayoría, obras de gran formato y están realizados con gouaches (con pinceladas puntuales de óleo) sobre papel de baja calidad, un material industrial que los hacía resistentes pero relativamente efímeros. Además, los métodos de trabajo de Sorolla resultaban una complicación adicional, ya que había recortado figuras y escenas individuales para después pegarlas en nuevas composiciones, en muchos casos con la adhesión de varios estratos en un mismo panel.

Con anterioridad a la intervención se realizó un informe pormenorizado del estado de conservación de cada uno de los treinta y dos bocetos. Presentaban un deterioro acusado, consecuencia, sobre todo, de la adherencia de distintos materiales y la diferente tracción que estos provocan por la interacción con los agentes ambientales. Por un lado, todos descansaban sobre una tela de algodón como soporte auxiliar que se encontraba en un proceso de 

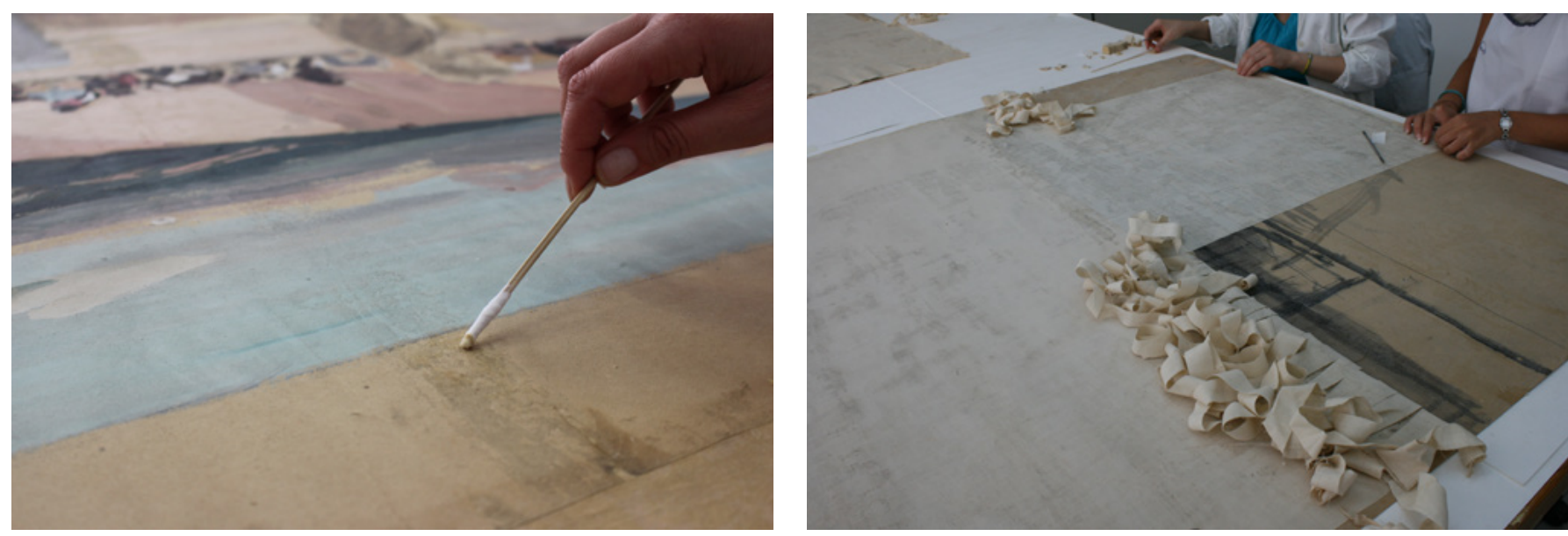

Limpieza de los restos de adhesivo del reverso, a la izquierda

degradación bastante avanzado y que no resolvía el problema de sujeción tal y como fue concebido; además, originaban importantes tensiones al tener ambos soportes un comportamiento diferente ante las variaciones de los parámetros de humedad relativa ambiental. Por otro lado, se ha podido constatar que Sorolla "reparó" algunos de estos bocetos con una tela engomada por el reverso, lo que resulta evidente en algunas intervenciones ya que los dibujos se componen, en muchos casos, de recortes realizados por el artista en los que solapa figuras y diferentes vestimentas e incluso ambientes. Estas estructuras también han generado importantes problemas de craquelados, distensiones, deformación e incluso rasgados de gran tamaño, por el empleo de adhesivo en exceso y la no preocupación en su superposición. Se trata de obras que Joaquín Sorolla pintó para él, sin esperar que salieran a la luz. De hecho, se advierte en su factura un artista muy diferente al que nos tiene acostumbrados, más estructural y conceptual, con una pincelada muy rápida con la que es capaz de construir "con poco un todo" en una importante composición. En muchos de los bocetos se advierte el trazo previo de carboncillo y algunos de ellos se conservan en esta técnica, sobre todo los referidos al estudio y diseño de la distribución de los grandes paneles en la biblioteca de la Hispanic Society. La capa pictórica presentaba una capa de suciedad superficial provocada por la polución ambiental. En la época en que llegaron los dibujos a Nueva York (hacia 1920) la calefacción de la zona de Harlem era de carbón, esto explica que estas piezas soportaran una capa superficial bastante intensa de partículas sólidas de carbón que terminó apagando la viveza de los colores empleados por el artista.

\section{ESTUDIOS PREVIOS Y PROCESO DE INTERVENCIÓN}

Tal y como se ha señalado, la técnica de ejecución de todos los bocetos es al gouache sobre papel por una cara, a excepción de uno de ellos, que se 


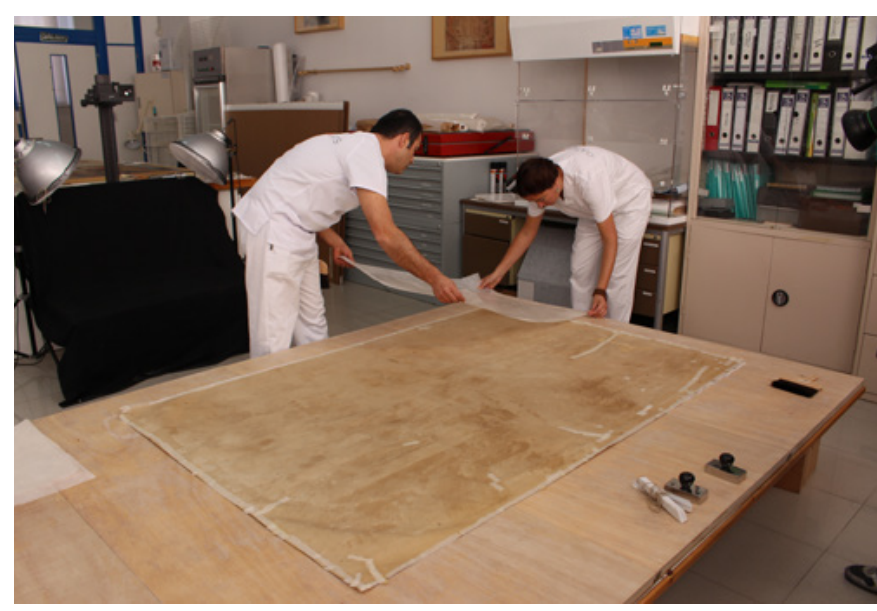

encuentra dibujado por las dos caras, de las cuales una ha sido esbozada con carboncillo.

Al tratarse de obras de gran formato sobre papel con elementos sustentados solubles, después de evaluar los resultados de los diversos estudios previos e investigaciones y barajar distintas posibilidades, se estimó que la técnica que mejor se podía adaptar al proceso de recuperación de la obra era la técnica japonesa sōkō que ha demostrado su eficacia por la simplicidad, ductilidad y respeto a la obra sobre papel, gracias al empleo de materiales naturales que respetan al máximo la obra y la impronta creativa del artista.

La necesidad de retirar la tela fue la más ponderada y valorada por el peligro estructural que esto suponía, por lo que la decisión fue tomada después de realizar varias pruebas, y con una propuesta de sustitución del soporte auxiliar que pasaba por una laminación con papel japonés.

En primer lugar, se llevó a cabo la documentación fotográfica de alta resolución que permitía examinar la naturaleza de estas piezas y ver con detalle los deterioros, para facilitar su posible y posterior intervención.

Acontinuación se realizaron análisis "no destructivos" mediante Fluorescencia de Rayos X Dispersiva en Energía (EDXRF), en colaboración con el Instituto de Ciencia de los Materiales de la Universidad de Valencia (ICMUV).

Los espectros EDXRF de los bocetos de Sorolla fueron registrados "in situ" en el IVCR+i mediante un espectrómetro portátil integrado por un tubo de rayos-X miniaturizado con ánodo de transmisión de plata que puede operar hasta $35 \mathrm{kV}$ y $0.1 \mathrm{~mA}$ y un detector de semiconductor Si-PIN con una resolución en energía de 165eV (FWHM @ 5.9 keV). Los análisis se efectuaron con incidencia normal del haz de rayos- $X$ sobre los bocetos y manteniendo 


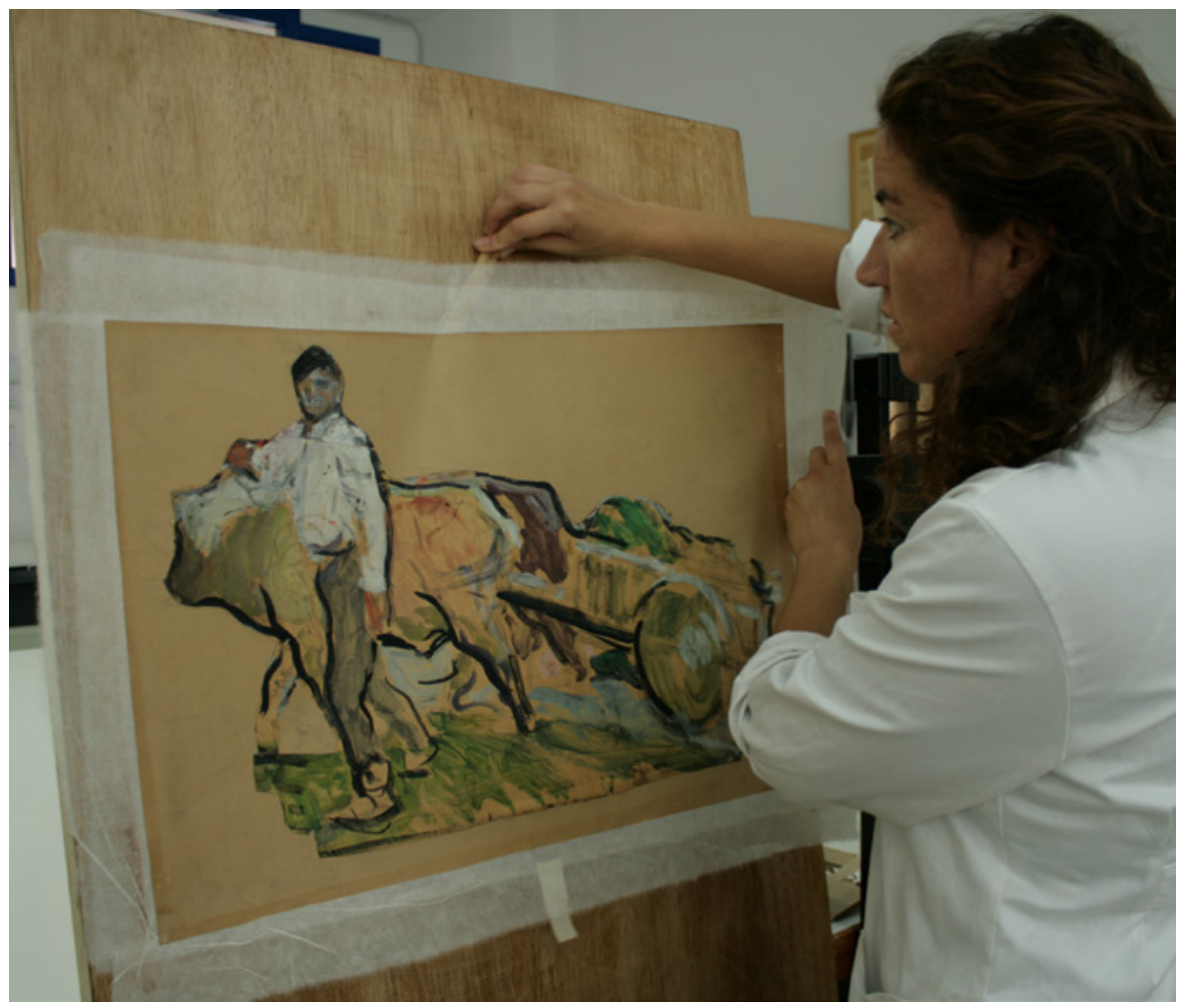

Secado y reparación de un boceto laminado del soporte de madera fenólica

el detector a un ángulo de $45^{\circ}$ respecto a dicha normal y con un tiempo de excitación-detección de 180 s. Se realizaron un total de 640 análisis de pigmentos y soportes de papel de los bocetos. El número de puntos analizados en cada boceto está en función de sus dimensiones y de las variedades cromáticas observadas. En cada uno de los puntos de análisis correspondientes a los pigmentos se registraron los elementos químicos característicos y a partir de ellos se procedió a su identificación, basada en el color característico y la correlación entre los elementos detectados y los denominados "key elements" de un pigmento dado (p. e., la detección de S y $\mathrm{Hg}$ en un pigmento rojo se correlaciona con el pigmento rojo bermellón, cuya composición química es sulfuro de mercurio, HgS). Mediante esta técnica analítica se procedió a la identificación de la paleta cromática empleada por Sorolla en los bocetos.

Por otro lado, y de forma puntual, se tomaron micro muestras de algunos pigmentos en los que era más difícil determinar su naturaleza con la técnica descrita con anterioridad. Con este tipo de muestras se han realizado análisis de determinación elemental mediante microscopia óptica y microscopia electrónica de barrido (SEM) acoplada a un equipo de análisis mediante dispersión de rayos $X$. Con estas técnicas se han determinado los diferentes tipos de pigmentos, principalmente en los tonos azules y grises. También ha 
permitido evaluar si existe superposición de capas pictóricas en los bocetos, lo que es indicio de modificaciones en su composición y elaboración.

Una vez realizados todos los estudios previos a la intervención, se optó por realizar varias pruebas y valorar el peligro estructural de sustituir el soporte auxiliar de tela del reverso por una laminación con papel japonés.

Antes de proceder a la eliminación de la tela de algodón, se llevó a cabo la limpieza en seco de la película pictórica. Después de realizar pruebas con gomas de distinta dureza, se comprobó que las esponjas de látex de textura muy suave y flexibles (usadas para maquillaje) no alteraban la superficie pictórica y eran las que menos residuo dejaban. Por otro lado, para la limpieza del soporte sin presencia de gouache, se optó por una esponja de caucho vulcanizado natural con carga de carbonato cálcico, cuya fuerza de arrastre de la suciedad es mayor y deja poco residuo.

Dada la naturaleza de las obras, bocetos pintados in situ, se ha considerado que la limpieza debía ser limitada y poco insistente. Del mismo modo, se han respetado, como parte del proceso artístico y como datos inherentes a la obra, los restos de adhesivo de los collages realizados por Sorolla, así como las manchas de carboncillo e incluso las huellas dactilares encontradas, que probablemente sean del artista.

El proceso de restauración se inició con los bocetos más pequeños con el fin de calibrar el alcance de la intervención y su problemática.

Tras la limpieza de la superficie pictórica, se procedió a la eliminación de la tela. Previamente, se estimó que, como medida preventiva, convenía una mínima consolidación de la capa pictórica que conferiría más seguridad al proceso de remoción del soporte auxiliar. De entre los consolidantes naturales se seleccionaron la gelatina (Tipo B, bloom 200), por ser las la más efectiva en la fijación de carboncillos, y el funori, por su inocuidad para el gouache.

Con el fin de evaluar si el proceso de consolidación producía algún tipo de alteración en el color, se escogieron zonas de diferente tonalidad y se realizaron medidas de color antes y después del proceso de consolidación. Los resultados mostraron que el cambio de color era imperceptible. La aplicación de ambos adhesivos se hizo al $1 \%$ a través de un nebulizador de ultrasonidos. Sólo en aquellas zonas donde la capa pictórica alcanzaba un volumen mayor y existían craqueladuras, la consolidación necesitó de una intervención más directa, esta vez con pincel y al $2 \%$, evitando un exceso de humedad que pudiera remover el pigmento.

En el reverso de las obras la suciedad acumulada era mayor que en el anverso, por lo que se aspiraron cada uno de los bocetos antes de retirar 
la tela. Para esta intervención, dado que el adhesivo había cristalizado, se aplicó una presión moderada al separar la tela de la obra. Con el fin de evitar daños colaterales al papel, se comenzó con la extracción de la tela a tiras y se frenó la tensión con el apoyo de la mano contraria. Después se efectuó el lijado manual de la superficie (con lijas de agua con abrasión reducida) con el propósito de eliminar los restos de adhesivo y, por último, se concluyó la operación con una aspiración final del reverso que deja el papel libre de residuos sólidos.

En la mayoría de los bocetos la eliminación de la tela se realizó siguiendo el mismo procedimiento, excepto la serie "Escena de Castilla", formada por tres paneles separados referentes a Castilla que conforman un solo en conjunto. Estos tres paneles eran los que estaban en peor estado de conservación, con numerosos rasgados, lagunas y deformaciones, que fueron ya reparadas por el propio autor con cinta de tela adhesiva y en los que se solapan distintas capas de papel. Para la remoción de la cola que adhería la tela al soporte, se necesitó la ayuda de geles que revirtieran su poder adhesivo. Se realizaron pruebas con Vanzan, Carbopol y Laponite (en agua al 5-10\%); este último fue el que mejor resultado ofreció. La dificultad con estos tres bocetos venía acrecentada por la deformación que producía el aporte mínimo de humedad de este tratamiento. Se decidió aprovechar esta coyuntura para ir eliminando, paralelamente, las deformaciones más importantes. Para remover los restos de adhesivo que quedaron tras la aplicación del gel, se emplearon torundas de algodón levemente impregnadas en agua templada.

Para proseguir con la restauración se reforzó prácticamente toda la zona perimetral por el reverso y se repararon los rasgados con papel Mino Tengujo $(9 \mathrm{~g} / \mathrm{m})$.

La fase más importante de la intervención fue la laminación de las obras por el reverso, con un papel cuya flexibilidad y resistencia fuera capaz de soportar el original. Para ello se eligió el papel japonés Sekishu. Este papel está realizado con la corteza interior de un arbusto, Kozo, que se cuece con un agente alcalino -mortero de cal- para eliminar sustancias no deseadas como la pectina y la lignina. Posteriormente, se blanquea con sustancias químicas y se seca al sol sobre planchas de acero inoxidable. Tiene un gramaje medio de $19 \mathrm{~g} / \mathrm{m}^{2}$ y unas fibras largas de kozo que lo han dotado de la elasticidad y fortaleza necesaria para la laminación. Como único adhesivo se ha utilizado el almidón de trigo. Para realizar este proceso, fue necesaria la fabricación de una mesa con maderas fenólicas y acabado con cera microcristalina, apta para la laminación, con el propósito de regular el exceso de humedad.

Para los bocetos de menor tamaño la metodología fue la siguiente: primero, se realizó el tensado perimetral de la obra con el uso de bandas y, en segundo lugar, se procedió a la laminación. 


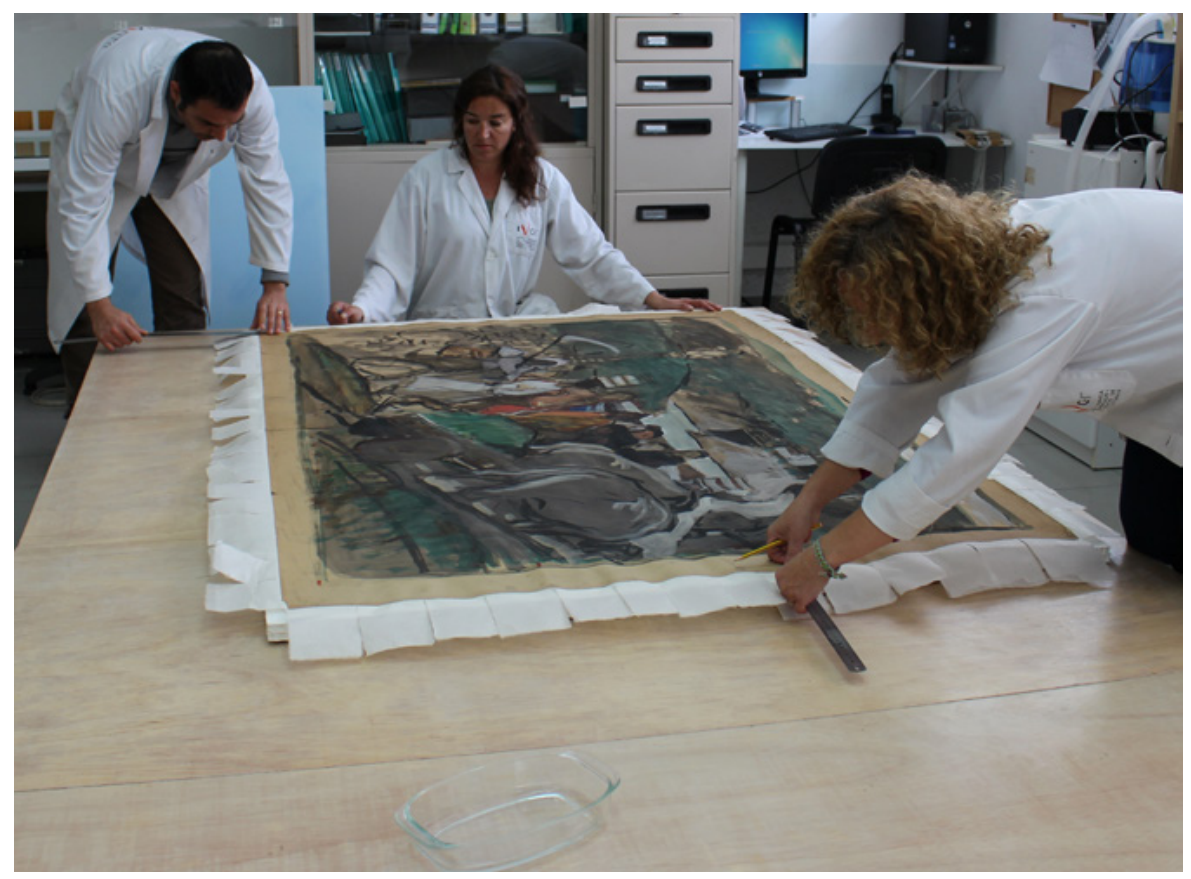

Preparación de las bandas de sujección flotante para su adhesión en el cartón Tycore

A continuación, se describen los pasos que se siguieron:

Se humectó levemente la obra por el anverso utilizando el nebulizador de agua Preservation pencil, que permite un aporte mínimo de humedad en frío. Por el reverso se aplicó propionato de calcio en espray, con el fin de dejar una reserva alcalina, ya que a pesar de que los resultados de medición del pH dieron valores en torno al 6,5\%, muy cercanos a la neutralidad, se estimó que un leve aporte alcalino podría contribuir a la preservación del original. La humedad se repartió de un modo homogéneo con ayuda de una brocha tipo Nadebake (brocha de fibra vegetal de palma). Se colocó el original con el dibujo hacia abajo sobre la mesa descrita y se cortaron tiras de papel sekishu de $12 \mathrm{~cm}$ de ancho y a contrafibra del original. Las tiras de papel se impregnaron con almidón y se adhirieron un centímetro sobre el borde del reverso del original, mientras que el resto se adhirió a la madera. A medida que las tiras de papel secaban, el boceto se tensaba y una vez seco la obra se separaba de la madera con ayuda de una plegadera de bambú (takebara).

El proceso de laminación se comenzaba cortando los papeles a contrafibra de la obra y diseñando el modo en el que se iban a colocar los fragmentos para cubrir todo el soporte, con el objeto de repartir las tensiones, evitando de esta manera que coincidieran las esquinas de los trozos y dejando un sobrante de unos 10-12 cm que coincidía con las bandas ya colocadas. La operación de humectación de la obra era igual en este caso, siempre 


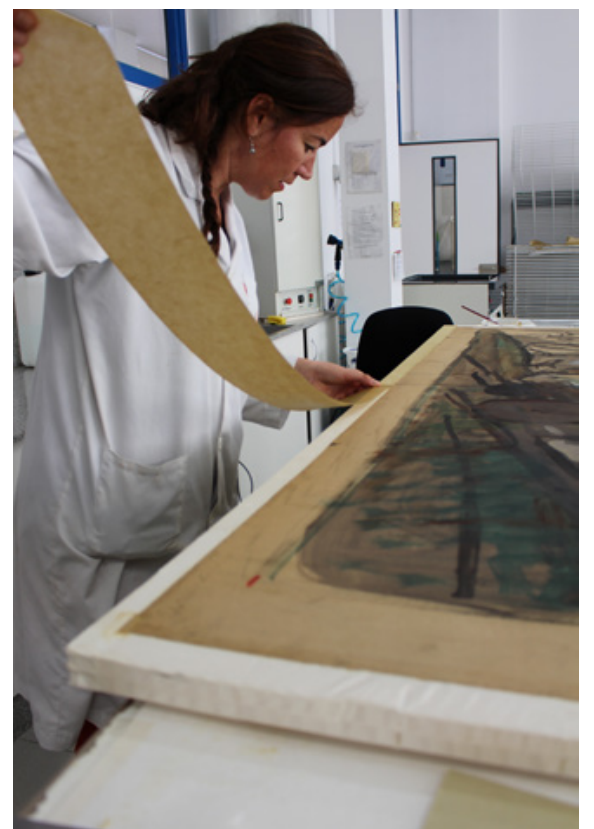

Adhesión de bandas coloreadas para homogeneizar los márgenes teniendo la precaución de interponer un hollytex entre la pieza y la madera fenólica. A continuación se aplicaba almidón (con una brocha de pelo de caballo o cabra, denominada Noribake) en los fragmentos de papel japonés sobre la mesa, con el fin de eliminar la máxima humedad posible antes de colocarlos sobre la obra; en la ejecución de esta acción era necesario apoyar los recortes de papel japonés sobre un hollytex, que facilitara su separación de la madera, transportarlos y adherirlos al reverso del boceto. Se han utilizado unas guías como referente al distribuir los fragmentos de papel sobre el original, una vez que éstos eran colocados, se asentaban con la ayuda de una brocha tipo Nadebake, realizando enérgicos movimientos de dentro hacia fuera que eliminaban el aire. El papel sobrante de la laminación se adhería a las bandas previamente colocadas y con una brocha se aplicaba nuevamente almidón, adhiriendo el papel a la madera. Durante el secado, de manera gradual se eliminaban las deformaciones, obteniendo el alisado de la obra. Una vez que la laminación y los bordes estaban totalmente secos, el sobrante de papel japonés alrededor del perímetro del original se separaba de la madera y se empleaba en el montaje final de la obra sobre cartones.

En los bocetos de tamaño superior a un metro, se comenzaron a tener dificultades con las bandas de tensión, por lo que se tuvieron que realizar pruebas hasta encontrar la solución adecuada para los grandes formatos. A pesar de que las maquetas eran de menor tamaño, por la dinámica de secado y comportamiento de los papeles, se consideró que la solución más adecuada pasaba por una doble laminación, una a contrafibra, y otra a fibra, ambas con el mismo papel y gramaje empleado hasta el momento.

La dificultad se hizo mayor con los grandes formatos de más de dos metros. El principal problema fue la humectación de la pieza, el girarla cuando estaba húmeda y la realización del secado con la obra boca abajo.

Para los japoneses la restauración de papel es el dominio en el control de la humedad y el modo de aplicarla, y no hay afirmación más cierta cuando se trata de operaciones de este tipo. Ya que, para una correcta laminación, la obra debe estar húmeda durante todo el proceso, con el fin de provocar tensiones y deformaciones. Del mismo modo, conviene que las laminaciones se efectúen una inmediatamente después de la anterior para evitar someter al papel a un nuevo momento de estrés con la aplicación de humedad. Estas laminaciones requieren tiempo y una actitud relajada, y se necesita un equipo de, al menos, cuatro personas para poder acompasar los tiempos. La colocación de los fragmentos de papel en húmedo, ahora de tamaño mayor, requiere de la ayuda de un listón de madera que los mantenga firmes. Una vez colocados, se confunden con el color del original y la madera, por lo que resulta harto complicado ir completando y casando los distintos fragmentos. Para ello se utilizó como apoyo un hilo de cáñamo sujetado a dos listones de 


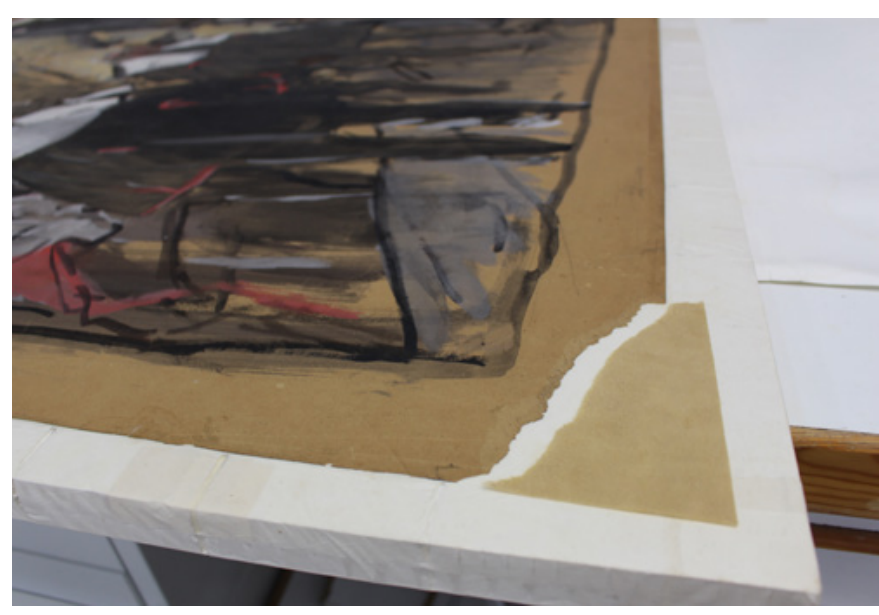

mármol, a modo de nivel, que marcaban la línea de colocación, solapando, en medio centímetro, uno sobre otro.

En este caso concreto, el resultado, aunque ha mejorado notablemente el original, no ha sido suficiente para eliminar todas las deformaciones del soporte, por el hecho de que, como hemos comentado, muchos de los bocetos no se componen solamente de una capa de papel, sino que el artista ha realizado sus composiciones con la adhesión de hasta 11 capas documentadas.

Durante este proceso, el secado se prolongaba varias horas por lo que era conveniente vigilar la obra durante este tiempo para evitar el rasgado de las bandas. Finalmente, convenía separarlo de la tabla una vez seco.

Con el fin de preservar los bocetos de cara a exposiciones y su futuro almacenamiento, se consideró que era conveniente dotarlos de un soporte rígido que facilitara su manipulación y movilidad. Después de evaluar los cartones disponibles aptos para la conservación, se optó por el Tycore como solución más conveniente, tanto por su neutralidad de Ph aprox. 8, como por su estabilidad dimensional, que lo convierten en un material ideal para un montaje de grandes dimensiones ligero y resistente.

Así pues, a los bordes que sobresalían de cada boceto se recortaban longitudinalmente, desfibradas tiras del papel sekishu de $34 \mathrm{~g} / \mathrm{m} 2$ que habían sido adheridas sobre el canto, en pestañas para el montaje al cartón con almidón, de modo que la obra quedaba "flotando" sobre este soporte rígido y las tiras regulaban la tensión y los posibles cambios de humedad.

Para las obras de gran tamaño se adhirieron dos cartones con adhesivo en espray para evitar un aporte de humedad innecesario. A la izquierda, realización de injertos con papel
sekishu

A la derecha, adhesión de las bandas perimetrales al soporte auxiliar 


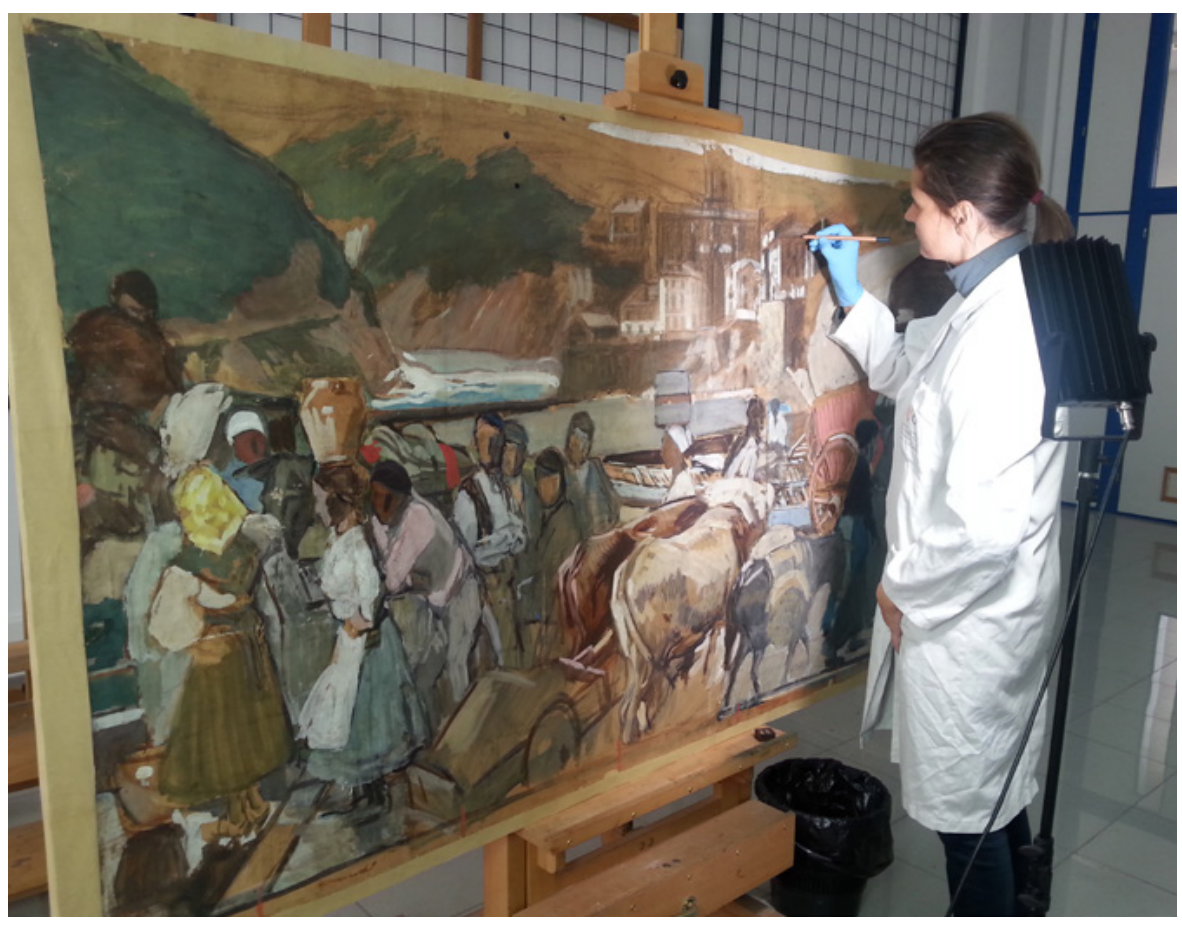

A petición del conservador de la Hispanic Society, se dejó un margen de unos tres centímetros para facilitar el transporte y la manipulación de las piezas. No obstante, una vez montados los dibujos, se consideró que ese borde resultaba agresivo para la legibilidad de la obra, por lo que se decidió su coloración.

El nivel de acabado de estos bocetos dista mucho de los preceptos de una obra "terminada", por lo que la reintegración cromática se limitó a la integración de aquellas partes que por su deterioro dificultaban la lectura del diseño inicial. Con el propósito de que fuera un proceso lo más reversible posible, se emplearon lápices de pastel y acuarelables y, sólo de manera puntual, acuarelas.

Ha sido un auténtico reto y un privilegio intervenir obras de esta categoría, de un Sorolla más íntimo y, a pesar de las numerosas dificultades, nos hemos sentido recompensados con los resultados obtenidos en la aplicación de esta técnica tradicional japonesa.

\section{CONCLUSIÓN}

Para terminar, nos gustaría resaltar la importancia que ha supuesto ver reconocido nuestro trabajo con el Premio Unión Europea de Patrimonio Cultural/ Premio Europa Nostra en su edición de 2018. 
Europa Nostra es la Federación pan-Europea de Organizaciones No Gubernamentales relacionadas con el Patrimonio, apoyada por una amplia red de instituciones públicas, organizaciones privadas y particulares de 40 países. Fundada en 1963, representa la voz de la sociedad civil para la conservación del Patrimonio Cultural y Natural de Europa, y actualmente se la reconoce como la organización de patrimonio más representativa e influyente en el continente europeo. Esta institución reconoce la excelencia mediante el Premio Unión Europea de Patrimonio Cultural/Premios Europa Nostra, que han servido para potenciar el sector del patrimonio en Europa destacando las buenas prácticas, fomentando el intercambio de conocimientos entre fronteras y conectando a las partes interesadas en redes más amplias. Además han permitido otorgar una mayor difusión a nivel nacional e internacional de las instituciones premiadas, además de favorecer un incremento del interés del público en general por nuestro patrimonio común destacando su intrínseco carácter europeo.

Joaquín Sorolla constituye uno de los valores universales que simbolizan lo mejor del talento artístico valenciano. Este proyecto de conservación y restauración ha permitido que un artista valenciano y por ende europeo haya sido estudiado y valorado desde un punto de vista muy diferente al habitual, dado que estos bocetos los hizo Sorolla para sí mismo y muestran su personalidad, su esfuerzo y dedicación en cada trabajo, y una capacidad de innovación que no resulta tan evidente en sus obras finales. Supone el acto creativo cumbre de este gran artista valenciano, además del verdadero epílogo y síntesis de toda su producción.

Con este trabajo que incluye instituciones europeas y americanas, se ha conseguido dar a conocer (en su momento íntimo de creación) a un artista europeo y se ha proyectado la imagen nueva de un Sorolla más innovador del que la historia del arte había catalogado.

Tal y como destacó el Jurado de Europa Nostra cuando concedió al IVCR+I el premio Unión Europea de Patrimonio Cultural/Premio Europa Nostra: "Este proyecto muestra una reflexión sobre la evolución de una obra de arte poniendo el foco de atención en el proceso y no sólo en el resultado final. Este conjunto muestra el interés de Norte América por un artista fundamental para la cultura europea del siglo XX. Este trabajo ha sido llevado a cabo por un Instituto europeo que ha respondido a ese interés de una forma ejemplar. El vínculo entre ambas instituciones es digno de mención". 